\title{
Nano Carbon as the Anode of Li Ions Batteries
}

\author{
Xiaofeng Fan* \\ 130012, China \\ *Corresponding author: Xiaofeng Fan, College of Materials Science and Engineering, \\ Jilin University, Changchun, 130012, China. Email: xffan@jlu.edu.cn
}

Key Laboratory of Automobile Materials (Jilin University), Ministry of Education, and College of Materials Science and Engineering, Jilin University, Changchun,

Received Date: June 06, 2019

Published Date: June 10, 2019

\begin{abstract}
Lithium ions batteries (LIBs) have been used in portable devices wildly and have potential applications in hybrid vehicles, electric vehicles and smart grids. The graphite-like carbon materials make a vital role in the development of LIBs. It is predictable that the development of carbon materials and related techniques will boost the performances and applications of LIBs further. Here we glance over the progress of carbon materials and the application as anodes in LIBs.
\end{abstract}

\section{Introduction}

Among the different kinds of electrochemical energy storage systems, lithium ions batteries (LIBs) have been one of the most promising. In LIBs, the charge/discharge is based on the mechanism of rocking chair in which Li ions shift back and forth easily between cathode and anode by crossing the electrolyte with a porous polymer separator. The cathodes are usually made with Li transition metal oxide, such as $\mathrm{LiCoO}_{2}$ and $\mathrm{LiMn}_{2} \mathrm{O}_{4}$ on $\mathrm{Al}$ foil. The electrolyte is composed by the organic liquids, such as PC, EC and DEC, with Li salts, such as $\mathrm{LiPF}_{6}$ and $\mathrm{LiBF}_{4}$. The anode can be $\mathrm{Li}$ metal on $\mathrm{Cu}$ foil with high theoretical capacity of 3860 $\mathrm{mA} \mathrm{h} / \mathrm{g}$. However, the formation of Li dendrite on the Li metal surface results in the serious safety issues and cycle stability. The use of carbonaceous materials (introduced by Sony Corporation, 1991) in anode promotes obviously the solution of safety issues and results in the broad use of LIBs in modern life, especially in portable electronic devices, such as laptops, mobile phones, cardiac pacemakers, and so on [1].

\section{Hard carbons and soft carbons}

Carbonaceous materials are obtained by heat treating of the carbon-contained precursors, such as polymers, fibers and cokes. With the heating temperature and time, there are significant changes in the microstructure, texture and morphology. Typically, there are two kinds of carbonaceous materials including hard carbon and soft carbon [2]. Hard carbons, also named by non-graphitic carbons, are prepared by pyrolysis of precursors under low temperature less than $1800 \mathrm{~K}$. Soft carbons, also named graphite-like crystallites, are produced by high temperature heating of precursors around $3300 \mathrm{~K}$. In hard carbons, there are graphitic-like segments cross linked strongly by $\mathrm{sp}^{3}$-hyrbidized carbon atoms with amorphous embedding areas. In soft carbon, the interaction between layers is weak. In high temperature, the cross linking between layers is weakened and the layers can be free to mobile to form graphiticlike structures. Compared to hard carbons, the soft carbons in intercalation/deintercalation processes of $\mathrm{Li}$ ions have good rate performance and stable insert potential. In recent most LIBs, soft carbons or graphitic structures are used as the anode.

\section{Nano structuring of materials and carbon nanotubes}

The disadvantage of graphite-like carbon structures is the low theoretical capacity of $372 \mathrm{mAh} / \mathrm{g}$. One of promising ways to enhance the capacity of batteries is to use the Nano structures as the electrodes [3]. Among the different carbon nanostructures, such as disordered carbon and acid treated graphite, carbon nanotubes (CNTs) have been explored widely to use in LIBs, especially as the conductive additives [4]. Single wall CNTs (SWCNTs) can be regarded as the single-atom layer cylinder by rolling up graphene seamlessly. Multiple sheets are rolled up together to form multi-walled CNTs (MWCNTs) with the distance of about $0.34 \mathrm{~nm}$ between concentric layers, like that in graphite. The electronic properties of SWCNTs are decided by its chirality and the considerable effort is on developing methods to control the chirality and purity of CNTs. CNTs can be synthesized by different methods, such as arc-discharge, laser vaporization and chemical vapor deposition with appropriate catalyst. CNTs are with a high 
electrical conductivity $\left(5 \times 10^{5} \mathrm{~S} / \mathrm{m}\right.$ at room temperature) and can be used as conductive additives for either anode or cathode. In the electrode, by just merging into SWCNTs with mass loadings of $0.2 \%$, a good conductivity can be achieved [5]. The capacity of free-standing SWCNT as the anode of LIBs is between 400-460 $\mathrm{mAh} / \mathrm{g}$ [6]. By shortening the SWCNTs and introducing defects in sidewall, the capacity is evaluated to approach to about $700 \mathrm{mAh} / \mathrm{g}$ [7]. Flexible electrode can be made by CNT papers. The reversible capacity of CNT/carbon layer paper can approach to $572 \mathrm{mAh} / \mathrm{g}$ [8]. Li can be stored between graphitic-like layers and inside of central tubes. The strain on the planar carbon six ring induced by the small diameters of CNTs is considered to make the structure more electronegative and enhance the adsorption of Li ions. The introduction of defects and more edge states due to the shorting of length can enhance the Li adsorption and decrease the diffusion length of Li in CNTs. These factors can boost the storage ability of Li in CNTs, compared to graphite.

\section{Doped graphene, defective graphene and graphdiyne}

In graphite, six carbon atoms can hold one $\mathrm{Li}$ to form $\mathrm{LiC}_{6}$ with the intercalation of $\mathrm{Li}$ between carbon layers. It is proposed that graphene can store more $\mathrm{Li}$ atoms than graphite, due to its double atomic surfaces. The interaction between $\mathrm{Li}$ and graphene is by the charge transfer and van der Waals (vdW) effect. The coulomb interaction is controlled by the charge transfer and therefore decided mainly by electronic structure. Therefore, the coulomb interaction in graphene is like in graphite. With the vdW effect, the adsorption of Li on graphene is a little weaker than in graphite. In the pristine graphene, the capacity should be less than $372 \mathrm{mAh} / \mathrm{g}$ with the possible formation of small Li clusters [9]. By introducing the vacancies/pores or defects on graphene, the adsorption of $\mathrm{Li}$ becomes to be stronger, with the enhancement of capacity [10]. The reversible capacity of disordered graphene nanosheets can be up to 794-1054 mAh/g [11]. Oxidized graphene nanoribbons have a reversible capacity of $800 \mathrm{mAh} / \mathrm{g}$ [12]. The doped graphene, such as B-doping and $\mathrm{N}$-doping, shows a high reversible capacity of more than $1040 \mathrm{mAh} / \mathrm{g}$ at rate of $50 \mathrm{~mA} / \mathrm{g}$ [13]. Graphdiyne is a single atomic layer with high pore ratio, since it is composed by the carbon six rings and short carbon chains. It is proposed that graphdiyne sheets have potential high capacities. It is reported that the revisable capacity of graphdiyne can be up to $520 \mathrm{mAh} / \mathrm{g}$ at rate of $0.5 \mathrm{~A} / \mathrm{g}$ [14].

\section{Nano composites with CNTs/graphene}

CNTs/graphene can offer a lightweight and stable supporting structure for other ultra-high capacity active materials which usually have the issues of volume expansion, due to the incorporation of $\mathrm{Li}$, such as $\mathrm{Si}, \mathrm{Ge}, \mathrm{Sn}, \mathrm{SnO}_{2}, \mathrm{SnSb}$, and $\mathrm{Fe}_{3} \mathrm{O}_{4}$. For examples, the freestanding SWCNT electrode with the incorporation of Nano-silicon particles (size of $50 \mathrm{~nm}$ ) shows a high reversible capacity of 584

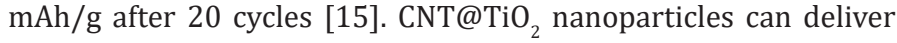
a capacity of $850 \mathrm{mAh} / \mathrm{g}$ after 65 cycles [16]. $\mathrm{SnO}_{2} /$ graphene nanocomposites exhibit a reversible capacity of $810 \mathrm{mAh} / \mathrm{g}$ at $50 \mathrm{~mA} / \mathrm{g}$ [17]. The composite of graphene nanosheets with $\mathrm{Fe}_{3} \mathrm{O}_{4}$ particles can deliver $580 \mathrm{mAh} / \mathrm{g}$ at $700 \mathrm{~mA} / \mathrm{g}$ after 100 cycles [18].

\section{Conclusion}

From the soft carbons/graphite to carbon nanostructures, such as graphene/CNTs/graphdiyne and nanocomposites with CNTs/graphene, the capacities have been boosted obviously and thus the performance of anode has been enhanced. Nano carbons can be also used in cathode as efficient conductive additives. It is foreseeable that Nano carbons will make a major role in the coming new-generation LIBs.

\section{Acknowledgement}

The research was supported by the National Natural Science Foundation of China (Grant No. 11504123 and No.51627805)

\section{Conflict of Interest}

No conflict of interest.

\section{References}

1 Goodenough JB, Park KS (2013) The Li-ion rechargeable battery: a perspective. J Am Chem Soc 135(4): 1167-1176.

2 Endo M, Kim C, Nishimura K, Fujino T, Miyashita K (2000) Recent development of carbon materials for Li ion batteries. Carbon 38(2): 183197

3 Ji L, Lin Z, Alcoutlabi M, Zhang X (2011) Recent developments in nanostructured anode materials for rechargeable lithium-ion batteries. Energy \& Environmental Science 4(8): 2682-2699.

4 Landi BJ, Ganter MJ, Cress CD, DiLeo RA, Raffaelle RP (2009) Carbon nanotubes for lithium ion batteries. Energy Environ. Sci 2(6): 638-654.

5 Landi BJ, Raffaelle RP, Heben MJ, Alleman JL, VanDerveer W, et al. (2002) Single Wall Carbon Nanotube-Nafion Composite Actuators. Nano Lett 2(11): 1329-1332.

6 Frackowiak E, Béguin F (2002) Electrochemical storage of energy in carbon nanotubes and nanostructured carbons. Carbon 40(10): 17751787.

7 Shimoda H, Gao B, Tang XP, Kleinhammes A, Fleming L, et al. (2002) Lithium intercalation into opened single-wall carbon nanotubes: storage capacity and electronic properties. Phys Rev Lett 88(1): 015502.

8 Chen J, Minett AI, Liu Y, Lynam C, Sherrell P, et al. (2008) Direct Growth of Flexible Carbon Nanotube Electrodes. Adv Mater 20(3): 566-570.

9 Fan X, Zheng WT, Kuo JL, Singh DJ (2013) Adsorption of single Li and the formation of small Li clusters on graphene for the anode of lithium-ion batteries. ACS Appl Mater Interfaces 5(16): 7793-7797.

10 Fan X, Zheng WT, Kuo JL (2012) Adsorption and Diffusion of Li on Pristine and Defective Graphene. ACS Appl Mater Interfaces 4(5): 2432 2438.

11 Pan D, Wang S, Zhao B, Wu M, Zhang H, et al. (2009) Li Storage Properties of Disordered Graphene Nanosheets. Chem Mater 21(14): 3136-3142.

12 Bhardwaj T, Antic A, Pavan B, Barone V, Fahlman BD (2010) Enhanced electrochemical lithium storage by graphene nanoribbons. J Am Chem Soc 132(36): 12556-12558.

13 Wu ZS, Ren W, Xu L, Li F, Cheng HM (2011) Doped graphene sheets as anode materials with superhigh rate and large capacity for lithium ion batteries. ACS Nano 5(7): 5463-5471.

14 Huang C, Zhang S, Liu H, Li Y, Cui G, et al. (2015) Graphdiyne for high capacity and long-life lithium storage. Nano Energy 11: 481-489.

15 Zhang Y, Zhang XG, Zhang HL, Zhao ZG, Li F, et al. (2006) Composite anode material of silicon/graphite/carbon nanotubes for Li-ion batteries. Electrochimica Acta 51(23): 4994-5000.

16 Zhang HX, Feng C, Zhai YC, Jiang KL, Li QQ et al. (2009) Cross-Stacked Carbon Nanotube Sheets Uniformly Loaded with $\mathrm{SnO}_{2}$ Nanoparticles: A Novel Binder-Free and High-Capacity Anode Material for Lithium-Ion Batteries. Adv Mater 21(22): 2299-2304. 
17 Paek SM, Yoo E, Honma I (2009) Enhanced cyclic performance and lithium storage capacity of $\mathrm{SnO}_{2}$ /graphene nanoporous electrodes with three-dimensionally delaminated flexible structure. Nano Lett 9(1): 72 75 .
18 Zhou G, Wang DW, Li F, Zhang L, Li N, et al. (2010) Graphene-Wrapped $\mathrm{Fe}_{3} \mathrm{O}_{4}$ Anode Material with Improved Reversible Capacity and Cyclic Stability for Lithium Ion Batteries. Chem Mater 22(18): 5306-5313. 